\title{
CONFLICTIVIDAD SOCIAL EN EL CAMPO CASTELLANO-LEONÉS DURANTE LA CRISIS DEL SISTEMA PARLAMENTARIO DE LA RESTAURA- CIÓN: LA TIERRA DE CAMPOS ENTRE 1917-1923 ${ }^{1}$
}

\author{
Jesús Ángel REDONDO CARDEÑOSO \\ Instituto Universitario de Historia Simancas.Universidad de Valladolid
}

\begin{abstract}
RESUMEN: En el siguiente trabajo hemos analizado las diversas manifestaciones de protesta colectiva que tuvieron lugar en la región castellano-leonesa de la Tierra de Campos durante los años de la crisis del sistema parlamentario de la Restauración (1917-1923). Con este estudio pretendemos mostrar cómo el campesinado la España agraria del interior no fue ajeno a la convulsión social que caracterizó esos años, desterrando del estereotipo del campesino castellano sumiso e indiferente a las cuestiones políticas, sociales y económicas de su época.
\end{abstract}

PALABRAS CLAVE: conflictividad social, huelga, motín, campesinado, Tierra de Campos.

ABSTRACT: In the next study, we have analized the several actions of colective protest that it took place in the region of Castile and León called Tierra de Campos during the parliamentary system's crisis of the Spanish monarchy's Restoration (1917-1923). With this research, we try to show that the peasantry of the inland agrarian Spain was not outside to the social upheaval of those years, and to eliminate the Castilian submissive peasantry's stereotype.

KEYWORDS: social disputes, strike, riot, peasantry, Tierra de Campos.

\section{INTRODUCCIÓN}

La Tierra de Campos es una comarca que se sitúa en el corazón de la actual comunidad autónoma de Castilla y León, ocupando importantes áreas de las provincias de Palencia, Valladolid y Zamora, además de un puñado de municipios

${ }^{1}$ Recibido para su publicación el 3 de septiembre y aprobado para su publicación el 22 de septiembre de 2009. 
de León ${ }^{2}$, con una extensión cercana a los $5000 \mathrm{~km}^{2}$.

Su economía se ha basado esencialmente en el sector agrícola, concretamente en una alta especialización del cultivo triguero. El sector social predominante en la comarca, a igual que ocurría en el resto de Castilla la Vieja y León, era un pequeño-mediano propietario que complementaba el trabajo en sus propiedades con la explotación de tierras en arriendo e incluso el trabajo asalariado en las épocas de mayor demanda laboral, como el verano, cuando se realizaba la recolección de los cereales ${ }^{3}$; aunque, en la Tierra de Campos en concreto no era despreciable la presencia de jornaleros, alcanzando cotas del $40 \%{ }^{4}$. La situación de ambos sectores sociales rozaba la miseria ${ }^{5}$.

Esta precariedad de la mayor parte de la sociedad terracampina hizo que la comarca fuera foco de no pocas agitaciones sociales. Durante el siglo XIX es de destacar cómo los motines de 1847 tuvieron su eco en poblaciones de la comarca como Becerril de Campos y Fuentes de Nava, ambas en Palencia ${ }^{6}$; y, sobre todo, el gran protagonismo de la región en las agitaciones sociales del verano de $1856^{7}$. Ya

* Este trabajo ha sido posible gracias a la Beca de Formación de Personal Investigador (Orden EDU/918/2006 de 30 de mayo) de la Consejería de Educación de la Junta de Castilla y León, cofinanciada por el Fondo Social Europeo.

** Las abreviaturas utilizadas en este texto en las notas a pie de página son, para las publicaciones periódicas: Boletín del Instituto de Reformas Sociales (BIRS); El Diario Palentino (DP); El Día de Palencia (DdP); Diario Regional (DR); El Norte de Castilla (NC); y Heraldo de Zamora (HZ). Y en lo que se refiere a los archivos: Archivo Histórico Nacional (AHN); Archivo de la Real Chancillería de Valladolid (ARChV), Archivo Histórico Provincial de Palencia (AHPP) y Archivo Histórico Provincial de Zamora (AHPZ).

${ }^{2}$ En este trabajo nos centraremos en las áreas de la comarca que se incluyen en las provincias de Palencia, Valladolid y Zamora, en concreto 162 municipios que contaban en 1920 con una población de hecho de 132.338 habitantes, siendo los municipios más poblados Medina de Rioseco (Valladolid) con 4.791 vecinos, y Paredes de Nava (Palencia) con 4.613 (I.N.E.: Censo de población de 1920).

${ }^{3}$ HeRmida REVILlas, C. (1989). Economía agraria y agitaciones campesinas en Castilla la Vieja y León: 1900-1936. Madrid: Editorial de la Universidad Complutense de Madrid, p. 7.

4 PÉrez SÁnChez, G. A. (2002). «La entrada de Castilla y León en el siglo XX (1898-1936)». En Bringas LóPEZ, M. I. y Rodríguez PAJARES, E. J. (dir. y coord.). Aproximación a la historia de Castilla y León. Épocas Moderna y Contemporánea. Burgos: Universidad para la Educación y Cultura de Burgos/ Asociación Fomento de Educación de Adultos, p. 145.

5 Hernández, R. y Moreno, J. (2009). «El nivel de vida en el medio rural de Castilla y León. Una constatación antropométrica, 1840-1970». Historia Agraria, 47, pp. 151-153.

${ }^{6}$ Díaz MARín, P. (2003). «Crisis de subsistencia y protesta popular: los motines de 1847 ». Historia Agraria, 30, p. 48.

${ }^{7}$ En Medina de Rioseco y Calahorra de Ribas la multitud atacó las fábricas de harinas; además se produjeron agitaciones en Carrión de los Condes, Villalón de Campos y Villalpando, e incendios de mieses en Villavicencio de los Caballeros, Paredes de Nava, Carrión de los Condes, Berrueces y 
en el siglo XX, la Tierra de Campos, concretamente su sector vallisoletano, fue el centro de la oleada huelguística que protagonizó el campesinado castellano en $1904^{8}$. Vemos, por tanto, que esta comarca castellanovieja y leonesa fue un importante foco de conflictividad social, hecho que también queda manifestado en la época que estudiaremos a continuación.

Figura 1. Localización del sector territorial investigado

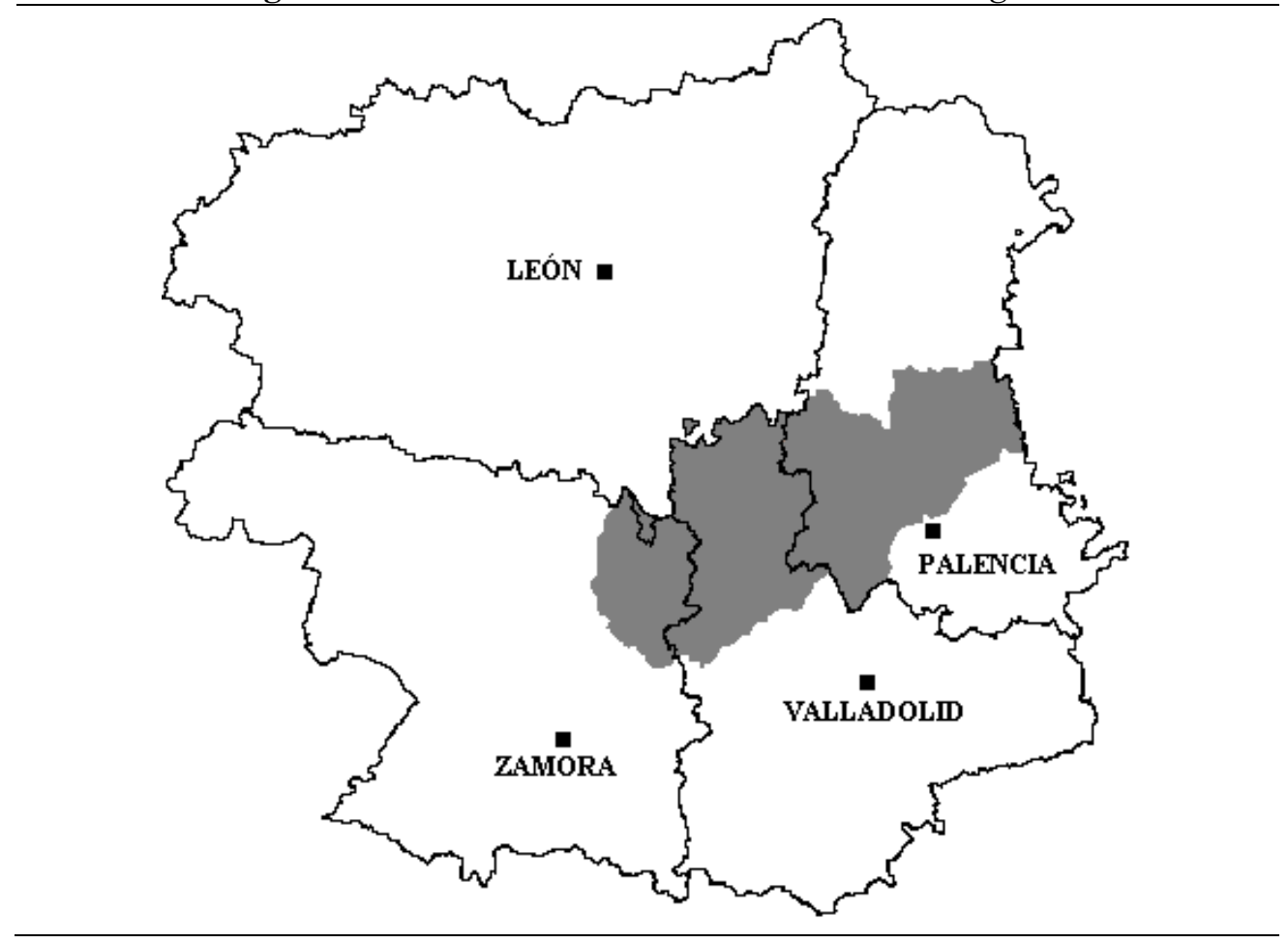

Diversos autores ya han señalado cómo en distintas regiones rurales de la España agraria interior (Granada, Badajoz, La Rioja, Castilla-La Mancha) la crisis del sistema parlamentario de la Restauración se desarrolló en medio de una notable

Villalpando; en: MoReno LÁzARO, J. (2003). «Fiscalidad y revueltas populares en Castilla y León durante el bienio progresista, 1854-1856». Historia Agraria. 31, pp. 128-135.

${ }^{8}$ Las agitaciones sociales de 1904 han sido estudiadas en: AróstegUI, J. (1977). Miseria y conciencia del campesinado castellano. Madrid: Narcea; y Biglino, P. (1986). El socialismo español y la cuestión agraria, 1890-1936. Madrid: Ministerio de Trabajo y Seguridad Social, pp. 57-64. 
conflictividad social, reflejo de que el campesino no fue un sujeto sumiso, ignorante y aferrado a su suerte, sino, muy por el contrario, que aceptó y utilizó las diversas formas de protesta colectiva, tanto tradicionales (motines, alborotos, tumultos), como las desarrolladas al amparo de las nuevas ideologías políticas de clase (huelgas) ${ }^{9}$.

El origen de la conflictividad de este período hay que buscarlo en un factor económico que influirá de forma determinante en las economías familiares: el drástico aumento en los precios de los artículos de primera necesidad ${ }^{10}$.

Figura 2. Índice del coste de la vida en la España rural, 1912-1923

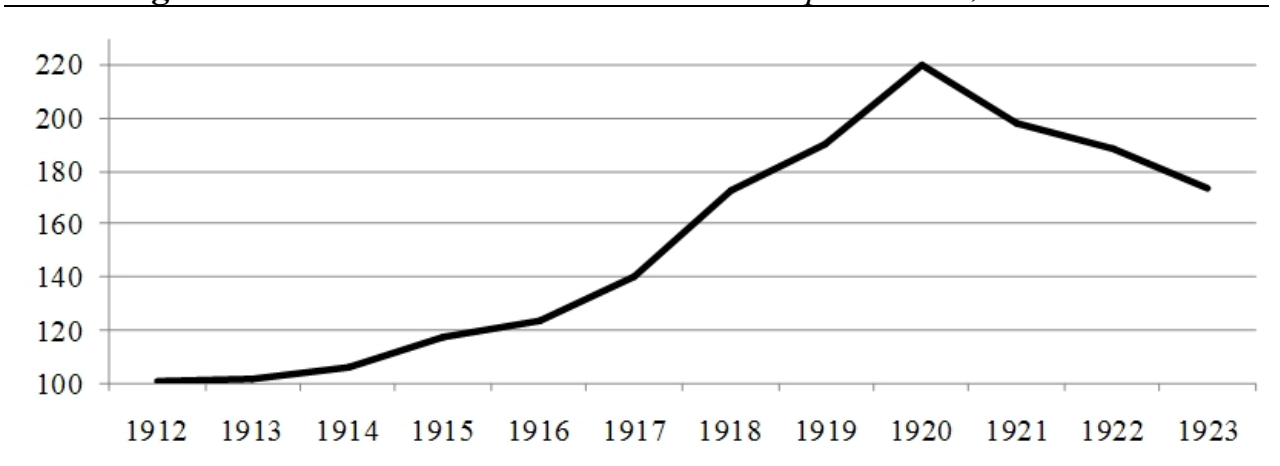

Fuente: Maluquer De Motes, J. (1989). «Precios, salarios y beneficios. La distribución funcional de la renta». En CARRERAS, A. (coord.). Estadísticas históricas de España. Siglos XIX-XX. Madrid: Fundación Banco Exterior, pp. 518-519.

${ }^{9}$ Cruz Artacho, S. (1994). Caciques y campesinos. Poder político, modernización agraria y conflictividad rural en Granada, 1890-1923. Madrid: Ediciones Libertarias/Ayto. de Córdoba; BAUMEISTER, M. (1996). Campesinos sin tierra. Supervivencia y resistencia en Extremadura (18801923). Badajoz: Diputación de Badajoz; GIL ANDRÉs, C. (2000). Echarse a la calle. Amotinados, huelguistas y revolucionarios (La Rioja, 1890-1936). Zaragoza: Prensas Universitarias de Zaragoza; BASCUÑÁn AÑover, Ó. (2008). Protesta y supervivencia. Movilización y desorden en una sociedad rural: Castilla-La Mancha. Alzira (Valencia): Fundación Instituto de Historia Social. También es digno de destacar en el estudio de la conflictividad social del campesinado, a pesar de que no se centre en nuestra época de estudio: LuCEA Ayala, V. (2005). Rebeldes y amotinados. Protesta popular y resistencia campesina en Zaragoza (1890-1905). Zaragoza: Institución «Fernando el Católico»/ Prensas Universitarias de Zaragoza.

${ }^{10}$ GonzÁlez CAlleja, E. (1999). El máuser y el sufragio. Orden público, subversión y violencia politica en la crisis de la Restauración (1917-1931). Madrid: C.S.I.C., p. 39. 
La conflictividad social durante la crisis del sistema parlamentario de la Restauración en las regiones de Castilla la Vieja y León fue un tema al que ya se acercó C. Hermida Revillas en su Tesis Doctoral, basándose en los datos que proporcionan las estadísticas del Instituto de Reformas Sociales ${ }^{11}$.

Figura 3. Huelgas en la Tierra de Campos según listado de C. H. Revillas

\begin{tabular}{ll}
\hline 1917 & Tordehumos (Vall.); Grijota (Pal.) \\
\hline 1919 & $\begin{array}{l}\text { Cuenca de Campos, Medina de Rioseco, Villalón de Campos (2), } \\
\text { Villabrágima, Palazuelo de Vedija (Vall.); Villalpando (Zam.); Grijota } \\
\text { (Pal.) }\end{array}$ \\
\hline 1920 & $\begin{array}{l}\text { Medina de Rioseco, San Pedro de Latarce, Villafrechós, Villalón de } \\
\text { Campos, Aguilar de Campos (Vall.); San Agustín del Pozo, Tapioles, } \\
\\
\text { Cañizo, Villalpando (Zam.); Fuentes de Valdepero, Monzón de Campos } \\
\text { (Pal.) }\end{array}$ \\
\hline 1921 & Cuenca de Campos, Villalón de Campos, Medina de Rioseco (Vall.) \\
\hline 1922 & Villalón de Campos (Vall.) \\
\hline 1923 & Tordehumos (Vall.) \\
\hline Fuente: Hermida RevilLas, C. (1989). Economía agraria y agitaciones..., pp. 395-399.
\end{tabular}

En nuestro caso, hemos ampliado la búsqueda de agitaciones sociales utilizando otro tipo de documentación, como la prensa y archivos gubernamentales y judiciales, observando que las acciones de protesta colectiva tuvieron mucho mayor calado en la comarca que el señalado por Hermida Revillas, y no sólo por el número de huelgas registradas, sino también por la diversidad de las manifestaciones de la protesta campesina. Un primer acercamiento cuantitativo muestra claramente este hecho.

Por otra parte, la evolución del Gráfico 4 nos confirma que la causa de la conflictividad social que estudiamos fue esencialmente el aumento de los precios de los productos básicos, ya que la evolución de ambos gráficos son similares, alcanzando sus más altas cotas en el año 1920, y reduciéndose drásticamente los índices a partir de ese año.

${ }^{11}$ La tesis doctoral de Hermida Revillas fue publicada por la Universidad Complutense de Madrid mediante una edición facsímil: Hermida REvillas, C. (1989). Economía agraria y agitaciones...; también podemos acercarnos a este mismo tema a través de: HeRmida Revillas, C. (1998). «Huelgas campesinas en Castilla la Vieja y León, 1900-1936». En ORTIZ DE ORTUÑO, J. M. y CASTILlo, S. (coords.): Estado, protesta y movimientos sociales. Actas del III Congreso de Historia Social de España. Bilbao: Universidad del País Vasco, pp. 613-624. 
Figura 4. Agitaciones sociales en la Tierra de Campos (1917-1923)

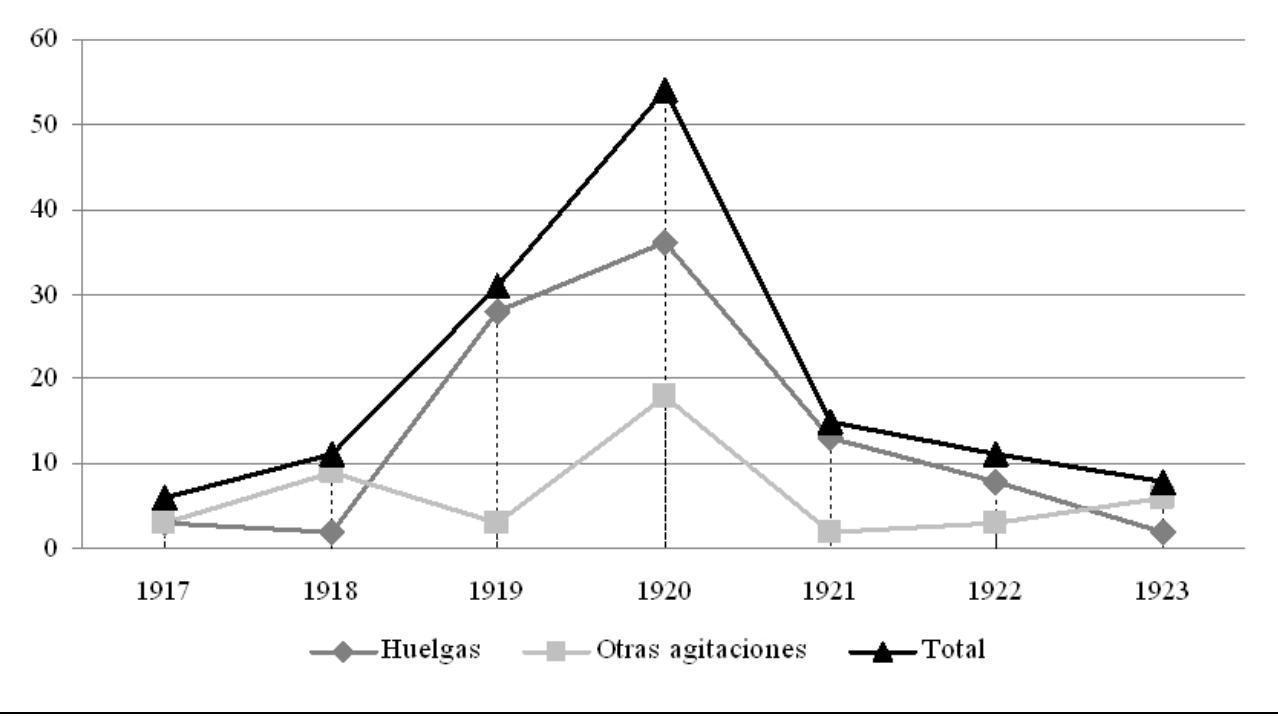

\section{HUELGAS}

"Los sucesos del verano de 1917 marcaron un hito en el desarrollo de la conflictividad social a todos los niveles..." ${ }^{12}$; hecho al cual no fueron ajenas las comunidades rurales españolas. Sin embargo, si bien la huelga general de agosto de 1917 tuvo éxito en ámbitos industriales, mineros y en algunas capitales de provincia, en el mundo rural pasó en gran medida inadvertida. En nuestra comarca de estudio la huelga de agosto se dejó sentir en la participación de "los obreros de la Compañía de Ferrocarriles de Castilla, que comprenden varias líneas en Palencia y Valladolid" ${ }^{\prime 3}$. A lo largo de ese año sólo se produjeron otras dos huelgas, ambas protagonizadas por obreros agrícolas: en Grijota y Tordehumos ${ }^{14}$. En 1918 el número de huelgas no aumentó, y de nuevo fueron los obreros agrícolas los que se

12 Aróstegui, J.; GonZÁlez Calleja, E. y Souto, S. (2002). «La violencia política en la España del siglo XX». Cuadernos de Historia Contemporánea, 22, p. 68.

${ }^{13}$ DdP: 20-8-1917. La Compañía de Ferrocarriles de Castilla gestionaba tres líneas de vía estrecha: Palencia-Villalón, Villada-Medina de Rioseco y Medina de Rioseco-Palanquinos; todas ellas atravesando municipios de la comarca, principalmente de los sectores palentino y vallisoletano.

${ }^{14}$ Ambas señaladas en Hermida Revillas, C. (1989). Economía agraria y agitaciones..., pp. 395-399; la de Tordehumos también en BIRS: ${ }^{\circ}$ 158, agosto 1917, pp. 146-147. 
declararon en huelga en abril en Grijota ${ }^{15}$, y en junio en la localidad zamorana de Fuentes de Ropel ${ }^{16}$. No fue hasta el año 1919 cuando la conflictividad socio-laboral eclosionó, principalmente con el protagonismo de los obreros agrícolas, aunque sin ser ajenos obreros de otros sectores laborales, principalmente los trabajadores del ferrocarril.

\subsection{Los obreros agrícolas}

En marzo de 1919 se declararon en huelga obreros agrícolas de Villada ${ }^{17}$; y en abril, a igual que ocurrió el año anterior, los de Grijota hicieron un paro reclamando aumento de salario ${ }^{18}$. A finales de mes, la huelga se declaró en Medina de Rioseco, resolviéndose por un acuerdo entre obreros y patronos a principios de mayo $^{19}$. El 30 de mayo se inició una huelga de obreros agrícolas en Villalpando que, con diversos altibajos, duró más de un $\operatorname{mes}^{20}$. Entre finales de junio y principios de julio, coincidiendo con el inicio de las labores de la recolección época en que los jornaleros obtenían los jornales más cuantiosos del ciclo laboral anual ${ }^{21}$, se sucedieron las huelgas en Villada y Ampudia (Palencia) ${ }^{22}$; Quintanilla del Monte y Quintanilla del Olmo (Zamora) ${ }^{23}$; y en Villafrechós, Villalón de Campos, Medina de Rioseco, Villabrágima y Mayorga (Valladolid) ${ }^{24}$, donde la huelga se mantuvo en pie hasta agosto; mes en el cual tuvo lugar la última huelga de ese verano en la localidad vallisoletana de Palazuelo de Vedija ${ }^{25}$.

La conflictividad se retomará en la comarca a inicios del otoño con la llegada de las labores de sementera, segunda época en importancia del jornal de los obreros agrícolas. Entre el 30 de septiembre y el 6 de octubre la huelga se desarrolló en

${ }^{15}$ DdP: 26-4-1918.

${ }^{16} H Z: 2-7-1918$.

${ }^{17} D d P: 29-3-1919 ;$ у $D P: 31-3-1919$.

${ }^{18}$ BIRS: $\mathrm{n}^{\circ} 179$, mayo 1919, pp. 552-553.

${ }^{19}$ BIRS: $\mathrm{n}^{\mathrm{o}} 180$, junio 1919 , pp. 692-693, y n 184 , octubre de 1919, pp. 422-423.

${ }^{20}$ BIRS: no 180 , junio 1919 , pp. 700-701; y HZ: 7, 14, 23 y 27-6-1919.

${ }^{21}$ Sobre la demanda de trabajo anual en los distintos tipo de cultivo y su remuneración ver RODRíGuez LABANDEIRA, J. (1991). El trabajo rural en España (1875-1936). Madrid: Anthropos, pp. $162-165$.

${ }^{22}$ La de Villada en $D d P$ : 13 y 17-6-1919; la de Ampudia en $D P$ : 27-6-1919.

${ }^{23}$ Ambas en HZ: 28-6-1919.

${ }^{24}$ La huelga de Villafrechós en DR: 26-6-1919; la de Villalón en DR: 3-7-1919 y BIRS: $\mathrm{n}^{\circ} 192$, junio 1920, pp. 882-883; las de Medina de Rioseco y Villabrágima en $B I R S, \mathrm{n}^{\circ} 182$, agosto 1919, pp. 154-155; la de Mayorga en $D R$ y $N C:$ 5-8-1919.

${ }^{25}$ DR: 12-8-1919. 
Tamariz de Campos (Valladolid), en petición de aumento de salario ${ }^{26}$. Prácticamente al mismo tiempo también hubo huelgas en Villafrechós, Villalón de Campos y Palazuelo de Vedija (Valladolid) ${ }^{27}$, todas ellas localidades donde se produjeron agitaciones en el verano; a igual que en Villada ${ }^{28}$, en el sector palentino de la comarca, área donde además se desarrollaron paros en Paredes de Nava y Carrión de los Condes $^{29}$.

El año terminaría con una huelga protagonizada por obreros del campo, mozos de labor y pastores en la localidad vallisoletana de Cuenca de Campos, entre el día 1 de diciembre y el 13 de enero de 1920, una huelga que fracasó ya que los huelguistas se quedaron sin trabajo ${ }^{30}$.

1920 fue, como ya hemos apuntado, el año en que la conflictividad sociolaboral en la comarca alcanzó su máximo apogeo. Los conflictos comenzaron en enero en tres pequeñas localidades de la Tierra de Campos zamorana: Tapioles ${ }^{31}$, San Agustín del Pozo ${ }^{32}$ y Cotanes del Monte, donde el paro se mantuvo hasta febrero $^{33}$. Durante la primavera se declararon huelgas en Villalpando ${ }^{34}$ y Medina de Rioseco ${ }^{35}$ en marzo; en Villalón de Campos a partir del 30 de abrii ${ }^{36}$; y en mayo en las localidades zamoranas de Villafáfila ${ }^{37}$ y Belver de los Montes ${ }^{38}$, donde los paros conectaron con los desarrollados en el inicio del verano, época que, de nuevo, concentró la mayor parte de los conflictos.

${ }^{26} N C$ : 1-6-1919; DR: 2 y 7-10-1919; y BIRS: no 185, noviembre 1919, pp. 602-603.

${ }^{27}$ La huelga de Villafrechós en $D R$ : 7 y 14-10-1919; la de Villalón en $D R$ : 8 y 17-10-1919, $N C$ : 10 y 18-10-1919, y BIRS: $\mathrm{n}^{\circ} 185$, noviembre 1919, pp. 608-609; la de Palazuelo de Vedija en BIRS: $\mathrm{n}^{\mathrm{o}}$ 185, noviembre 1919, pp. 608-609.

${ }^{28} D d P: 10$ y 13-10-1919, y BIRS: no 185 , noviembre 1919, pp. 608-609.

${ }^{29}$ La de Paredes en DP: 14-10-1919; la de Carrión en NC: 9-10-1919 y BIRS: $\mathrm{n}^{\mathrm{o}} 185$, noviembre 1919, pp. 606-607.

${ }^{30}$ BIRS: $\mathrm{n}^{\mathrm{os}} 187,188$ y 189 , enero, febrero y marzo de 1920 , pp. 236-237.

${ }^{31} H Z$ : 15 y 19-1-1920; BIRS: nos 187,188 y 189, enero, febrero y marzo de 1920, pp. 238-239.

${ }^{32} H Z$ : 19-1-1920; BIRS: $\mathrm{n}^{\text {os }} 187,188$ y 189, enero, febrero y marzo de 1920, pp. 238-239.

${ }^{33} H Z$ : 8-1-1920 y 4-2-1920.

${ }^{34}$ BIRS: $\mathrm{n}^{\circ}$ 191, mayo 1920, pp. 646-647.

35 BIRS: $\mathrm{n}^{\circ}$ 191, mayo 1920, pp. 648-649 y n ${ }^{\circ} 199$, enero de 1921, pp. 146-147.

${ }^{36}$ BIRS: $\mathrm{n}^{\mathrm{o}} 192$, junio 1920 , pp. 872-873.

${ }^{37} H Z$ : 5-5-1920 y 23-6-1920.

${ }^{38}$ HZ: 28-5-1920, 23-6-1920, 26-6-1920 y BIRS: nº 193, julio 1920, pp. 208-209. 
Entre junio y julio se declararon huelgas en Paredes de Nava, Monzón de Campos, Villada y Boadilla de Rioseco en la provincia de Palencia ${ }^{39}$; en el área zamorana en Tapioles, Fuentes de Ropel, Cañizo, Villarrín de Campos, Villamayor de Campos, Cerecinos de Campos, Revellinos, Castronuevo y Villalpando, donde tras declararse los obreros agrícolas en huelga a finales de junio la agitación se mantuvo hasta mediados de julio ${ }^{40}$; y en el área vallisoletana en San Pedro de Latarce, Villafrechós, Villalón de Campos, Palazuelo de Vedija, Cuenca de Campos, Santervás de Campos, Moral de la Reina, Mayorga y Aguilar de Campos ${ }^{41}$.

Tras el conflictivo año de 1920, las huelgas de obreros agrícolas se redujeron. El año 1921 comenzó con huelgas en Castromocho y Paredes de Nava, ambas en Palencia $^{42}$. Aunque será nuevamente el inicio del verano cuando los obreros del campo desarrollaron las acciones de protesta, extendiéndose las huelgas en los pueblos palentinos de Paredes de Nava y Villada ${ }^{43}$; y en los vallisoletanos de Palacios de Campos, Villalón de Campos, Palazuelo de Vedija, Moral de la Reina, Medina de Rioseco y Cuenca de Campos, declarándose esta última el 30 de junio y no solucionándose hasta agosto ${ }^{44}$.

${ }^{39}$ La huelga de Paredes en DdP: 30-6-1920; la de Monzón en DP: 26 y 28-6-1920, BIRS: ${ }^{\circ}$ 194, agosto 1920, pp. 436-437; la de Villada en DdP: 8 y 13-7-1920, BIRS: $\mathrm{n}^{\mathrm{o}} 195$, septiembre 1920, pp. 584-585 y n ${ }^{\circ} 204$, junio de 1921, pp. 1022-1023; la de Boadilla de Rioseco en DP: 13 y 22-7-1920.

${ }^{40}$ La huelga de Tapioles en HZ: 18-6-1920; la de Fuentes de Ropel en HZ: 25, 26 y 28-6-1920; Cañizo en BIRS: $\mathrm{n}^{\circ}$ 194, agosto 1920, pp. 434-435 y n 202, abril de 1921, pp. 658-659; Villarrín de C. en $H Z$ : 23-6-1920; Villamayor en HZ: 23 y 26-6-1920 y 20-7-1920; Cerecinos en HZ: 25, 26 y 286-1920, 7 y 20-7-1920, BIRS: $\mathrm{n}^{\circ}$ 195, septiembre 1920, pp. 586-587; Revellinos en HZ: 26-6-1920 y 2-7-1920; Castronuevo en HZ: 2-7-1920; y Villalpando en 23-6-1920, 1 y 9-7-1920, BIRS: $\mathrm{n}^{\circ}$ 194, agosto 1920, pp. 436-437.

${ }^{41}$ La huelga de San Pedro de Latarce en DR y NC: 24-6-1920, y BIRS: ${ }^{\circ} 194$, agosto 1920, pp. 436-437 y n 202 , abril de 1921, pp. 658-659; la de Villafrechós en DR: 1, 2 y 17-7-1920; y BIRS: ${ }^{\circ}$ 195 , septiembre 1920 , pp. 584-585 y n 202 , abril de 1921, pp. 662-663; la de Villalón en $D R: 3$ y 97-1920, y $B I R S: \mathrm{n}^{\circ} 195$, septiembre 1920, pp. 584-585; DR: 2 y 7-7-1920, y BIRS: $\mathrm{n}^{\circ} 195$, septiembre 1920, pp. 586-587; la de Cuenca de Campos en $D R$ : 7-7-1920; la de Santervás en $D R: 7,16$ y 17-71920, y $B I R S: \mathrm{n}^{\circ} 195$, septiembre 1920, pp. 584-585; la de Moral de la Reina y Mayorga en DR: 7-71920, y BIRS: $\mathrm{n}^{\circ} 195$, septiembre 1920, pp. 584-585; y la de Aguilar de Campos en DR: 13-7-1920, y BIRS: $\mathrm{n}^{\circ} 195$, septiembre 1920, pp. 588-589.

42 Ambas en DdP: 7-1-1920; además la de Castromocho en BIRS: nº 201, marzo 1921, pp. 480481; y la de Paredes de Nava en BIRS: $\mathrm{n}^{\circ} 202$, abril 1921, pp. 652-653.

${ }^{43}$ Respectivamente en $D P$ : 5-7-1921 y $D d P:$ 12-7-1921.

${ }^{44}$ La huelga de Palacios de Campos en $D R: 1$ y 6-7-1921; la de Villalón en $D R: 6,7,8$ y 16-71920, y BIRS: $\mathrm{n}^{\circ} 207$, septiembre 1921, pp. 416-417; la de Palazuelo en $D R$ y NC: 6-7-1921; la de Moral de la Reina en NC: 6-7-1921, y BIRS: $\mathrm{n}^{\circ}$ 207, septiembre 1921, pp. 414-415; la de Medina de Rioseco $D R: 15,23$ y 26-7-1921, y en BIRS: $\mathrm{n}^{\circ} 207$, septiembre 1921, pp. 414-415 y no 213, marzo de 
En 1922 sólo se produjeron huelgas de obreros agrícolas en Villalón de Campos $^{45}$ y Medina de Rioseco ${ }^{46}$, además de una amenaza de huelga en Carrión de los Condes $^{47}$. La última huelga agrícola del período tuvo lugar en 1923 en Tordehumos $^{48}$.

La mayoría de los conflictos reseñados tuvieron una causa económica, concretamente la petición de aumento de salario. Por lo que respecta a los participantes, éstos fueron comúnmente hombres, aunque no dejó de sentirse de vez en cuando la presencia de mujeres jornaleras, como las arrancadoras de legumbres de Paredes de Nava y Medina de Rioseco que protagonizaron las huelgas de junio de 1920 y julio de 1921, respectivamente; o las recogedoras de algarrobas en Villalpando, principales protagonistas de la huelga de junio de 1919, y donde se puede ver influencias de la teatralidad carnavalesca, con expresiones de inversión y lenguaje subversivo, tan características de las tradicionales acciones de protesta colectiva antiguorregimentales:

«Al no entenderse los interesados, las familias de los labradores comenzaron por sí mismas a proceder al arranque de las algarrobas. En vista de esto, las mujeres de los obreros, que son las más exaltadas, requirieron paraguas y sombrillas y en guisa de señoritas, se encaminaron a las eras y al campo. Al ser preguntadas por la guardia civil a dónde iban, contestaban que de paseo, situándose cerca de los labradores, sus mujeres e hijas, dirigiéndolas frases mortificantes y ofensivas y cantando cantares alusivos y alguno amenazador» ${ }^{49}$

También fue una característica general de las huelgas de jornaleros terracampinos la actitud pacífica de las partes litigantes, salvo algunos casos de coacciones similares al ejemplo señalado. Sólo en el verano de 1920, la época de mayor tensión conflictiva de la comarca, la actitud violenta se erigió en protagonista de los sucesos. En Villafrechós, el 28 de junio de 1920, varios huelguistas que impedían salir a trabajar a otros obreros se enfrentaron y

1922, pp. 754-755; y la de Cuenca de Campos en DR: 8, 16 y 28-7-1921 y 12-8-1921, y BIRS: no 206, agosto 1921, pp. 268-269 y n 212 , febrero de 1922, pp. 558-559.

${ }^{45} B I R S: \mathrm{n}^{\circ} 219$, septiembre 1922, pp. 610-611 y no 219 , septiembre de 1922, pp. 606-607.

${ }^{46} H Z, 13-7-1922$.

${ }^{47} D P: 13-7-1922$.

${ }^{48} D R:$ 5-7-1923; y BIRS: $\mathrm{n}^{\circ} 231$, septiembre 1923, pp. 832-833 y no 231, septiembre de 1923, p. 820.

${ }^{49} N C: 14-6-1919$. 
amenazaron al alcalde de la localidad cuando éste acudió a restablecer el orden ${ }^{50} ; \mathrm{y}$ tres obreros de la misma localidad, fueron juzgados en la Audiencia por un supuesto disparo de arma de fuego ese mismo día, aunque los procesados fueron absueltos por no quedar demostrados los hechos imputados ${ }^{51}$. La prensa, generalizando, señaló que entre obreros y patronos "se cruzaron disparos, palos y pedradas" $"$. Consecuencias más dramáticas tuvo la huelga de Cerecinos de Campos, concretamente los sucesos que tuvieron lugar el día 25 de junio, cuando la Guardia Civil realizó varios disparos contra un grupo de obreros que pretendían impedir los trabajos de una máquina segadora, resultando de la colisión un obrero muerto y tres heridos ${ }^{53}$.

En definitiva, el obrero agrícola terracampino no fue ajeno a la conflictividad socio-laboral que se extendió por el conjunto del territorio español de esos años, a pesar de la importante presencia e influencia que tuvo en la comarca el sindicalismo agrario católico desde $1912^{54}$. La larga lista de conflictos sociolaborales planteados por los obreros agrícolas reseñados en este apartado no deja lugar a dudas sobre este tema.

\subsection{Los obreros ferroviarios}

Los trabajadores del sector del ferrocarril siempre se han caracterizado por sus continuas acciones reivindicativas, y en la Tierra de Campos, comarca por donde a principios del siglo XX se extendían varias líneas ferroviarias, inevitablemente se debía de dejar sentir su conflictividad. Ya hemos visto la participación de los obreros de la Compañia de Ferrocarriles de Castilla en la huelga de agosto de 1917. Estos mismos obreros iniciaron un conflicto en enero de 1920 amenazando con ir a la huelga ${ }^{55}$; disputa que los mismos protagonistas retomaron en julio con otra amenaza de huelga que exigía de la empresa un aumento de salario ${ }^{56}$; lo cual también sucedió en noviembre de $1921^{57}$. Por su parte, los obreros del Ferrocarril

${ }^{50}$ ARChV: Sentencias criminales, año 1921, nº 20.

${ }^{51}$ ARChV: Sentencias criminales, año 1921, $\mathrm{n}^{\circ} 68$.

${ }^{52} \mathrm{DR}$ y $N C: 1-7-1920$.

${ }^{53} H Z: 25$ y 26-6-1920.

54 MartíneZ, M. (1982). Tierra de Campos. Cooperativismo y sindicalismo agrario. Valladolid: Institución Cultural Simancas/Diputación Provincial de Valladolid, p. 54.

${ }^{55}$ DdP: 21-1-1920.

${ }^{56} N C$ : 16 y 22-7-1920; $D R: 16$ y 22-7-1920; $D P: 21$ y 22-7-1920; $D d P: 21-7-1920$.

${ }^{57} D P: 2-11-1921$. 
Económico de Valladolid a Rioseco ${ }^{58}$ plantearon un conflicto en junio de 1920, amenaza que en un principio parece que se arregló al alcanzarse un acuerdo entre las partes; aunque éste no satisfizo a los obreros ya que se declararon en huelga el 2 de julio, basándose en que no se les había "abonado el aumento concedido",59.

Heredando esta conflictividad se desarrollará a partir de 1921 una serie de huelgas protagonizadas por un grupo de obreros ferroviarios muy concreto: los constructores de la doble vía de la línea Palencia-León gestionada por la Compañía de Ferrocarriles del Norte ${ }^{60}$. Estos obreros protagonizaron un primer conflicto en abril de 1921 en las obras localizadas en Paredes de Nava "por negarse el contratista a despedir a uno que no estaba asociado" ${ }^{\text {". }}$. La amenaza de huelga volvió al siguiente mes ${ }^{62}$. Ya en marzo de 1922 los obreros de Becerril de Campos se declararon en huelga pidiendo aumento de jornal ${ }^{63}$; y en abril los obreros de Cisneros pararon con la misma reivindicación, aunque no la consiguieron ${ }^{64}$. La última huelga protagonizada por estos obreros tuvo lugar a finales de la primavera de ese mismo año en Villada, motivada por "el despido de tres compañeros, despido que consideran injustificado todos los demás" $"$.

Sin embargo, la conflictividad que se vivió en la doble vía del ferrocarril Palencia-León tuvo otra manifestación bien distinta a la protesta colectiva: la violencia interpersonal entre obreros y capataces de obra. Varios ejemplos así lo atestiguan: en Villada fue detenido un obrero "por amenazas de muerte dirigidas al capataz del segundo grupo de obreros de la vía doble del Norte"66; en las obras de Becerril de Campos "discutieron acaloradamente el vecino de Paredes de Nava Alejandro Pajares, albañil, empleado en la construcción de la vía doble del ferrocarril del Norte, y el capataz de dichas obras", discusión que derivó en una

\footnotetext{
${ }^{58}$ Esta empresa gestionaba una línea de ferrocarril de vía estrecha, popularmente conocida como "Tren burra", que unía Medina de Rioseco con la capital vallisoletana, y que acabará siendo absorvida por la Compañía de Ferrocarriles de Castilla en el año 1930.

${ }^{59}$ DR: $12,16,18,19$ y 22-6-1920; 3 y 4-7-1920.

${ }^{60}$ La Compañía de Ferrocarriles del Norte, gestionaba las líneas de vía normal Palencia-León y Palencia-Santander, las cuales cruzaban la Tierra de Campos palentina.

${ }^{61} D d P: 14,19$ y $22-4-1921$.

${ }^{62}$ DP: 14-5-1921.

${ }^{63} D P: 9-3-1922$.

${ }^{64} D P$ y $D d P: 19-4-1922$.

${ }^{65} D d P: 1$ y 3-6-1922; y BIRS: $\mathrm{n}^{\mathrm{o}} 217$, julio 1922, pp. 218-219.

${ }^{66} D P: 3-5-1922$.
} 
agresión por la que fue detenido el primero ${ }^{67}$; en Cisneros fue detenido el capataz de obra porque, en discusión con un obrero, "llegó a amenazarle de muerte con una escopeta de caza que tenía en su poder" ${ }^{\circ}$; y, por último, siendo el hecho más grave, en Villada:

«... el día uno de Julio del año último pasado [1923] cuestionaron de palabra, en el pueblo de Villada, el capataz de la doble vía férrea del Norte, José María Abascal, y el obrero Vicente Felipe Encinas, reconviniendo éste a aquél por haber maltratado días antes a un hermano suyo, preparándose aquellos dos para acometerse con los palos que poseían, cuando, aglomerándose varios obreros que allí había, sonó un disparo de arma de fuego que a nadie hirió, ni concretamente puede asegurarse quien lo hizo, cercando dichos obreros al Abascal el cual resultó herido levemente en el cuello, brazo derecho y labio superior» ${ }^{69}$

\subsection{Otros sectores laborales}

Además de la importante conflictividad que protagonizaron los obreros agrícolas y, en segundo lugar, los ferroviarios, la declaración de huelgas tuvo otros protagonistas. Por ejemplo, es digno de reseñar las huelgas que llevaron a cabo los obreros de las fábricas de harinas de Villada en diciembre de $1919^{70}$ y abril y julio de $1920^{71}$. En Medina de Rioseco se declararon en huelga en octubre de 1919 los panaderos ${ }^{72}$ y los obreros de un taller mecánico, éstos exigiendo la jornada de ocho horas y el aumento de su salario en media peseta ${ }^{73}$. Asimismo los panaderos de Cuenca de Campos protagonizaron una huelga desarrollada paralelamente a la que efectuaron los obreros agrícolas de la localidad entre diciembre de 1919 y enero de $1920^{74}$.

Y no sólo se produjeron conflictos locales sino que también vemos influencias de las huelgas convocadas a nivel nacional, principalmente en los dos principales centros obreros de la comarca, Medina de Rioseco y Villada, donde se vieron

${ }^{67} D P: 3-7-1922$.

${ }^{68}$ DP: 23-8-1922.

${ }^{69}$ AHPP: Sentencias criminales, 1924, $\mathrm{n}^{\circ} 40$.

${ }^{70} \mathrm{DdP}: 11-12-1919$.

${ }^{71} D P: 8$ y 13-4-1920; $D d P: 7,12$ y 13-4-1920; y NC: 9-7-1920.

${ }^{72} N C: 24-10-1923$.

${ }^{73}$ BIRS: $\mathrm{n}^{\mathrm{0}} 185$, noviembre 1919, pp. 606-607; y n 195 , septiembre de 1920, pp. 600-601.

${ }^{74}$ BIRS: $\mathrm{n}^{\text {os }} 187,188$ y 189 , enero, febrero y marzo de 1920, pp. 236-237. 
afectados los servicios por la huelga de correos de agosto de $1922^{75}$; como también afectó a la última villa citada la huelga de telegrafistas de la primavera de 1919, de tal modo que se tuvo que encargar "al sobrestante de Obras públicas don Ramón Luzuriaga, que señale horas de oficina para recibir telefonemas que sean transmitidos a Palencia y poderse comunicar con toda la nación" ${ }^{, 76}$.

Otras huelgas fueron la de sirvientas que se produjo en Villalpando en mayo de $1919^{77}$, y la de obreros canteros en Paredes de Nava en junio de $1923^{78}$.

Resumiendo, y tras varias páginas señalando y describiendo huelgas, ¿quién puede seguir afirmando que la Tierra de Campos fue un mar de paz social durante la crisis del sistema parlamentario de la Restauración? Los hechos hablan por sí solos.

\section{MOTINES, TUMULTOS Y MANIFESTACIONES}

Si bien hasta el momento hemos analizado una forma de protesta como la huelga que parte de una organización previa, principalmente a la sombra de la existencia de un sindicato o agrupación política, ésta no fue la única forma de protesta colectiva que se produjo en la Tierra de Campos durante el período estudiado, sino que convivió, igual que sucedió en otras áreas rurales de la España del primer tercio del siglo XX, con formas de protesta colectiva tradicionales ${ }^{79}$. Éstas incluyen motines, tumultos o manifestaciones populares que no se producían al amparo de organizaciones políticas y sindicales, sino que eran expresión del descontento y malestar de la comunidad local ante determinados acontecimientos, principalmente, como no podía ser de otro modo ante una coyuntura económica de crisis aguda, por el encarecimiento de los artículos de primera necesidad.

\subsection{Manifestaciones y motines por las subsistencias}

Una de las principales preocupaciones de las clases populares durante la I Guerra Mundial fue el vertiginoso aumento de los precios de los artículos de primera necesidad. La preocupación se comenzó a dar desde 1917, de este modo en Medina de Rioseco, el 29 de noviembre, se celebró una manifestación con la

${ }^{75} N C: 25-8-1922$; y $D d P: 22-8-1922$.

${ }^{76} D d P: 25-4-1919$ y $2-5-1919$.

${ }^{77} H Z: 14-6-1919$.

${ }^{78}$ BIRS: $\mathrm{n}^{\circ} 230$, agosto 1923, pp. 560-561.

79 GIL ANDRÉS, C. (1998). «Los ecos del motín: percepción del Estado y de otros símbolos de poder en la España del primer tercio del siglo XX». En ORTIZ DE ORTUÑo, J. M. y CASTILlo, S. (coords.). Estado, protesta ..., p. 265. 
participación de las "fuerzas vivas" de la ciudad ${ }^{80}$ en la que se protestaba porque la dificultad de transportes dejaba desabastecida la localidad de productos de primera necesidad ${ }^{81}$. Sin embargo, no fue hasta 1918 cuando estas agitaciones comenzaron a extenderse por la comarca. Desde la prensa, y a lo largo del primer trimestre del año, se nos informa de cómo en distintos puntos de la comarca se perciben "ánimos excitados" entre las elites, principalmente por el establecimiento de la tasa del trigo ${ }^{82}$.

Éste fue el preludio de varias acciones protagonizadas por las clases populares en protesta por el aumento de los precios de las subsistencias. La primera de estas acciones se produjo en Villada, donde tuvo lugar una manifestación de mujeres el día 22 de abril ${ }^{83}$; manifestación de las mismas características se repitió en Villarramiel, en junio ${ }^{84}$; y pocos días después las mujeres de las clases populares de Paredes de Nava protagonizaron un motín impidiendo salir de la estación de ferrocarril de la villa dos vagones de trigo ya facturados, basándose en que la fábrica de harinas de la localidad había cerrado días antes por falta de ese cereal ${ }^{85}$.

Con la llegada del otoño las elites terracampinas volvieron a la carga, esta vez en contra de las incautaciones que propiciaba el R. D. de 10 agosto, amenazando incluso con no sembrar más trigo que el necesario para el autoconsumo de los municipios ${ }^{86}$. Y, de nuevo las clases populares, aunque minusvaloradas por la

${ }^{80}$ La participación de las élites locales en este tipo de manifestaciones no era algo desconocido, como ya ha señalado CRUZ ARTACHO, S. (2000). «De campesino a ladrón y delincuente en Andalucía (XIX-XX)». En GonZÁlez de MolinA, M. (ed.). La historia de Andalucía a debate. I. Campesinos y jornaleros, Barcelona: Anthropos/ Diputación Provincial de Granada, p. 174; ya que, como apunta P. Carasa, el poder local necesita del apoyo social, lo cual sólo se consigue atendiendo a las necesidades cotidianas e inmediatas de la comunidad local; ver CARASA SOTO, P. (2003). «Cambio de cultura política y poder local en la Castilla contemporánea». En CARASA SOTO, P. (coord.). El poder local en Castilla. Estudios sobre su ejercicio durante la Restauración (1874-1923). Valladolid: Universidad de Valladolid, pp. 10-11.

${ }^{81}$ DR: 6-12-1917.

${ }^{82}$ Como ejemplo se puede ver las distintas amenazas que a través de la prensa realizaron diversos sindicatos agrí́colas católicos como el de Villalpando (DR: 30-1-1918); Villacarralón (DR: 8-2-1918); Medina de Rioseco (DR: 8-3-1918) o Villafrades y Villalón de Campos (DR: 10-3-1918); más sobre la reacción de los labradores castellano-leoneses ante la tasa del trigo de 1918 en CALVo CABALLERo, P. (2003). Asociacionismo y cultura patronales en Castilla y León durante la Restauración (18761923). Valladolid: Junta de Castilla y León, pp. 116-121.

\footnotetext{
${ }^{83} D P$ y $D d P: 23-4-1918$.

${ }^{84} D d P: 21-6-1918$.

${ }^{85} D P$ y $D d P: 27-6-1918$.

${ }^{86} D R: 4$ y $10-9-1918$.
} 
epidemia de gripe, elevaron su voz. El vecindario de Villalón de Campos se apostó en las salidas del pueblo el 13 de noviembre con la firme intención de no dejar salir ni una almuenza de trigo de la localidad ${ }^{87} ; \mathrm{y}$, para terminar el año, de nuevo en Villada se produjo una manifestación de obreros con el beneplácito de la autoridad local reclamando:

«1. ${ }^{\circ}$ Que se haga bajar el precio de las subsistencias, comenzando por el pan, puesto que hasta el día de la fecha, que sin duda por la anunciada manifestación le han bajado cinco céntimos, el pan se ha estado vendiendo a 0'75 céntimos en las panaderías y 65 en la tahona, o sea al mismo precio que cuando el trigo se pagaba a 22 y medias pesetas la fanega.

2. ${ }^{\circ}$ Que si la fábrica de la luz no puede darla, se instale en la vía pública la antigua luz en faroles como estaba antes.

3. ${ }^{\circ}$ Que se abra el curso de la Escuela nocturna de adultos y se celebren las clases sin interrupción.

4. ${ }^{\circ}$ Que para la venta de todos los artículos de consumo se establezca con rigor el sistema métrico decimal y se abandone para siempre el antiguo sistema de libras. Y

5. ${ }^{\circ}$ Que si en el término de ocho días no son atendidas por la alcaldía las anteriores peticiones, los manifestantes se elevarían en respetuosa y razonada queja al señor gobernador» ${ }^{88}$

A pesar de todo, los sucesos de 1918 sólo fueron el preludio de la oleada de motines y manifestaciones que tuvieron lugar en la primera mitad de 1920. Las tres últimas cosechas habían sido pésimas, y los precios de las subsistencias no dejaban de subir. No es extraño, por tanto, que el año comenzase con una manifestación de obreros en Villalpando reclamando que se les diera trabajo iniciándose las obras de la carretera que conducía a Toro ${ }^{89}$. El 8 de marzo se produjo en Villada una manifestación contra el alza de las tarifas ferroviarias ${ }^{90}$; y el 10 de marzo tuvo que intervenir la Guardia Civil en una administración de tabaco de Medina de Rioseco que llevaba varios días sin género "para evitar abusos y escándalos" ". En la segunda quincena de abril se produjeron manifestaciones pidiendo el abaratamiento de las subsistencias en Villarramiel y Villada ${ }^{92}$; y en Roales de Campos estalló un motín "como consecuencia del cobro de un arbitrio municipal, que se negó a

${ }^{87} N C: 17-11-1918$.

${ }^{88}$ DdP: $10-12-1918$.

${ }^{89}$ AHN: Serie A Gobernación, leg. 41 A, exp. 24, carp. 23.

${ }^{90}$ AHN: Serie A Gobernación, leg. 41 A, exp. 25, carp. 29.

${ }^{91} N C: 12-3-1920$.

${ }^{92}$ DdP: 21-4-1920 y 24-4-1920. 
abonar parte del vecindario"93. El mes de mayo la conflictividad alcanzó su punto más álgido, sobre todo en el sector palentino de la comarca donde se produjeron manifestaciones pacíficas pidiendo el abaratamiento de las subsistencias en Cisneros $^{94}$, Carrión de los Condes ${ }^{95}$ y Villada ${ }^{96}$; aunque también se expresaron actitudes más violentas. En este sentido, en Grijota, y a igual que ocurrió con el caso de Paredes de Nava dos años antes, desde mediados de mayo las fábricas de harina de la localidad no entregaban género a los grijotanos, por lo que la mañana del 11 de mayo, cuando el vecindario se enteró que en la estación de ferrocarril de la localidad se iba a facturar un vagón de harina con destino a otra provincia, "el pueblo en masa y en actitud tumultuosa se dirigió a la estación impidiendo que la referida cantidad de harina fuese facturada" ${ }^{, 97}$. Similares sucesos tuvieron lugar en Carrión de los Condes, donde, pocos días después de la manifestación anteriormente señalada, "el vecindario ha impedido la salida de trigos y harinas" ${ }^{98}$; y en Fuentes de Valdepero, donde "existía gran disgusto entre los vecinos a causa de venderse el pan a una peseta el kilogramo", tuvo que intervenir fuerza de la Guardia Civil el día 24 "con motivo de la agitación que reina entre la clase obrera, que pide pan barato y aumento de jornales" $"$.

Parece ser que a partir de esta fecha la buena cosecha que se preveía y los primeros descensos de los precios aplacó el descontento popular, aunque todavía en agosto se siente la amenaza de nuevas agitaciones, tal como refleja el corresponsal del Heraldo de Zamora en Villalpando:

«Las sencillas gentes de esta villa se muestran muy excitadas, por ocurrir hechos que si se comprueban deben ser castigados.

A los labradores se les obliga a vender el trigo a precio de tasa y los harineros, verdaderos soberanos de la voluntad omnímoda en nuestro país, no quieren ceder la harina al precio que la ley les señala, no obstante, ser más que remunerador el margen de utilidades que les concede.

${ }^{93} N C: 30-4-1920$.

${ }^{94} \mathrm{DdP}: 3-5-1920$.

${ }^{95} D P$ : 17-5-1920; у $D d P: 18-5-1920$.

${ }^{96} D d P: 29-5-1920$; у $D P: 26$ у 29-5-1920, у 5-6-1920.

${ }^{97} D P$ : 11-5-1920; y $D d P, 12-5-1920$.

${ }^{98} D d P: 21-5-1920$.

${ }^{99} D P$ : $19-5-1920$ y $D d P: 25-5-1920$ (este suceso es señalado como una huelga por HeRMIDA Revillas, C. (1989). Economía agraria y agitaciones..., p. 398; aunque nosotros, a tenor de los acontecimientos que reflejan la prensa, entendemos que hay que considerarlo como un motín). 
Si la buena voluntad del alcalde accidental, don Maximiliano Peláez, no se hubiera puesto por medio, es casi seguro que Villalpando lamentaría a estas fechas algunas desgracias.

Amparo Granados y Felipa López, mujeres de obreros, han presentado una denuncia en la Alcaldía contra los harineros que no quieren ceder la harina a precio de tasa.

Y como consecuencia de ello, la agitación entre los elementos obreros ha surgido amenazadora» 100

\subsection{Violencia y política local}

Las protestas y revueltas populares también se utilizaron como una forma de oposición ante medidas que adoptaban los responsables del gobierno municipal y que podían ser consideradas abusivas, arbitrarias o simplemente contrarias a la costumbre local ${ }^{101}$. Ésta era la forma que tenía la comunidad campesina de participar en aquellos conflictos políticos locales que les afectaba de manera más inmediata. Entre estas cuestiones se encontraban aspectos como la gestión y aprovechamiento de los pastos del municipio. Por este motivo se produjo en mayo de 1920 un conato de motín del vecindario de Becerril de Campos, que necesitó la intervención del juez de instrucción del partido ${ }^{102}$; y en Valoria del Alcor tuvieron lugar unos violentos enfrentamientos entre bandos de vecinos en diciembre de 1918 tras un juicio contra un vecino de Ampudia "por intrusión de reses lanares en propiedad ajena", disturbios en los que resultaron heridos, por disparo de arma de fuego, el alcalde y el juez municipal del municipio ${ }^{103}$.

Otra causa de conflicto era el ejercicio de las funciones de los cargos municipales. Ejemplos son la "marejada" que vivió Capillas con "motivo del nombramiento de secretario del Ayuntamiento" "104; o el alboroto que se produjo en el vallisoletano pueblo de Villacarralón en mayo de 1918, donde parece ser que el guarda municipal del campo "al frente unas cuarenta personas" amenazó e insultó a tres guardas de la Asociación Nacional Española de Cazadores, Pescadores y Agricultores de Medina de Rioseco cuando fueron a denunciar a cuatro convecinos

100 HZ: 19-8-1920.

101 BAumeister, M. (1996). Campesinos sin tierra..., pp. 241-244; estas manifestaciones de violencia colectiva también han sido estudiadas por LUCEA AYALA, V. (2001-2002). «Protesta colectiva en Zaragoza en el tránsito del siglo XIX al XX: una tipología». Studia Histórica. Historia Contemporánea, 19-20, pp. 129-159; y BASCUÑán AÑover, O. (2008). Protesta y supervivencia..., pp. 151-154.

${ }^{102}$ DdP: $12-5-1920$.

${ }^{103}$ DP: 27 y 28-12-1918; y AHPP: Sentencias criminales, 1919, nº 66.

${ }^{104}$ DdP: 16-3-1920. 
de los primeros ${ }^{105}$. Así mismo, el desarrollo de las alianzas políticas del ayuntamiento de Paredes de Nava originó varios altercados violentos: el 28 de abril de 1918, en el Ayuntamiento, después de que "las minorías maurista e independiente" solicitaran "que se rindan las cuentas municipales de los años 1916 y 1917", y ante la negativa del alcalde, el público intentó agredirle,"llegando a subir al estrado en forma tumultuaria" y, pocos momentos después, "Hubo otra contestación que no fue del agrado del público y éste promovió un escándalo monumental, agrediendo al señor Herrezuelo y obligando a levantar la sesión, interviniendo la guardia civil" "106; y el 10 de febrero de 1923, en el mismo escenario, cuando el alcalde intentaba nombrar a dos concejales interinos se produjo el siguiente incidente:

«... estando lleno dicho salón, se protestó hostilmente por la posesión que tenía lugar, profiriéndose insultos a referido Don Samuel Pajares [uno de los concejales interinos] a quien terminado el acto, al salir del local en que se celebraba, repitiéndose las protestas, le maltrataron de obra, golpeándole sin causarle lesión» ${ }^{107}$

Otros motines originados en el ámbito de la gestión de la política local los encontramos en Villarramiel donde, al quedar desierta la subasta para contratar las vacas que se iban a lidiar en las fiestas patronales los días 24 y 25 de agosto de 1920, "parte del vecindario se amotinó, intentando agredir al alcalde", lo que obligó al Gobernador Civil a concentrar varias parejas de la Guardia Civil en la población bajo mando de un capitán ${ }^{108}$; en Villalpando fueron juzgados seis vecinos por "ultrajes a la Nación y contra el libre ejercicio del culto", cuando protestaron por la celebración de unas funciones religiosas que tenían como objeto "recaudar fondos para los soldados de aquella villa"109; y en Itero de la Vega, donde varios jóvenes, "con grandes cajones de piedras, con los que producían enorme ruido", realizaron una cencerrada en la parroquia contra el párroco, alcalde, regidor síndico y juez municipal, acción "atribuida a antiguas rencillas políticas", la cual, por culpa de una reyerta en la que intervino el hijo del alcalde y de la que resultó herido uno de los alborotadores, derivó en un motín donde "el padre del

105 ARChV: Sentencias criminales, $1919, \mathrm{n}^{\circ} 61$.

${ }^{106}$ DdP: 30-4-1918.

107 AHPP: Sentencias criminales, 1923, no 134; más noticias sobre el hecho en DP: 12 y 15-21923.

${ }^{108}$ DdP: 18-8-1920.

109 AHPZ: Sentencias criminales, año 1923, nº 143. 
herido y un numeroso grupo de jóvenes y varios vecinos, recorrieron el pueblo dando voces y gritos" y apedreando varias casas de sus rivales ${ }^{110}$.

En otro sentido, también destacaron algunas acciones reivindicativas contra los médicos: en abril de 1921 "cincuenta y cinco o sesenta familias del pueblo de Villoldo" protagonizaron una manifestación en el vecino Carrión de los Condes "por el proceder observado por el médico titular de aquel pueblo""111; en junio del mismo año "una nutrida comisión de vecinos pobres de Villalón [de Campos]" se presentó ante el Gobernador Civil de Valladolid para protestar contra el nombramiento del medico titular que era hijo del alcalde de la localidad; y, en el pueblo zamorano de Castroverde de Campos, se produjo una grave alteración del orden público en abril de 1923 en la que se enfrentaron violentamente dos bandos de vecinos, disturbios causados por "no querer parte de aquel vecindario la asistencia de uno de los dos médicos que allí existen", y de los que resultaron "dos heridos de arma blanca" ${ }^{\prime 12}$.

A pesar de todo, el momento de mayor tensión y proclive a la ejecución de actos de protesta colectiva relacionados con la política local fue la celebración de elecciones. Por esta razón, de cara a las elecciones municipales de noviembre de 1917, el alcalde de Villanueva del Campo reclamó la presencia de la Guardia Civil en la localidad porque se habían "enardecido los ánimos y se espera ocurran acontecimientos" $" 113$. En las elecciones a diputados a Cortes celebradas el 1 de junio de 1919 se produjeron altercados en Carrión de los Condes suspendiéndose la votación "ante los temores de que se alterase el orden, en vista de la actitud en que se hallaban algunos grupos"114; y en Villalón de Campos, tras la detención del jefe liberal de la localidad, "se empezaron a congregar grandes núcleos de obreros y amigos particulares y políticos del detenido en los alrededores del Ayuntamiento", por lo que se dejó sin efecto tal detención ${ }^{115}$. Pocos días después de estas elecciones, y durante la elección de compromisarios, en el pequeño pueblo palentino de Añoza se produjeron unos disturbios que obligaron a concentrar en la localidad fuerzas de la guardia civil provenientes de los puestos de Cisneros y Paredes de Nava ${ }^{116}$. También el alcalde de Becerril de Campos reclamó del

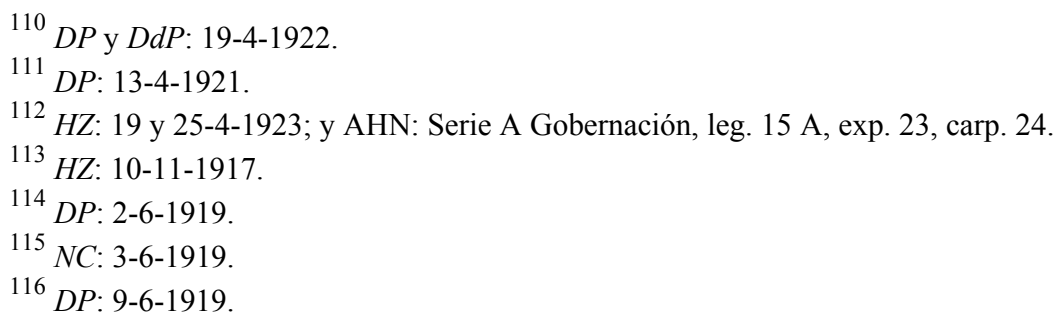


Gobernador Civil la presencia en la localidad de la Guardia Civil para las elecciones del 8 de febrero de $1920^{117}$. A pesar de ello, no se tuvieron noticias de altercaciones en este pueblo, ni tampoco en Villoldo "donde los ánimos estaban muy excitados", aunque sí llegaron rumores de desórdenes en Ampudia ${ }^{118}$. En las municipales del 5 de febrero de 1922, las minorías conservadora y socialista de la localidad de Melgar de Abajo denunciaron "delitos de coacción"119. El alcalde de Boadilla de Rioseco tuvo que pedir el auxilio de la Guardia Civil durante elecciones a Diputados Provinciales de junio de 1923 "por haberse alterado el orden en este pueblo a consecuencia de ciertas coacciones ejercidas" ${ }^{120}$; y, el mismo día, en Cisneros, se consiguieron celebrar las elecciones "después de algunos incidentes desagradables entre los electores, afortunadamente sin consecuencias que lamentar" ${ }^{\prime 21}$.

\subsection{Otros tipos de motines}

El 10 de junio de 1920 la Audiencia Provincial de Valladolid absolvía a seis vecinos de Aguilar de Campos del delito de sedición. A dichos individuos se les acusaba:

«... de haber promovido un grave tumulto en el pueblo de Aguilar de Campos, el cual se inició el día quince de Enero del mil novecientos veinte, y continuó al siguiente día, con objeto de conseguir, como al fin lo consiguieron, que fuera puesto a en libertad Vicente Molero Martínez, Secretario de la Sociedad obrera de dicho pueblo, a quien el Alcalde del mismo había denunciado por insultos a su autoridad, al Juez Municipal que se hallaba instruyendo las oportunas diligencias, que no sólo tuvo que interrumpir, si que también entregar a los tumultuarios quienes las rompieron» ${ }^{122}$

Este hecho, que en un principio parece parte de una acción enmarcada en una solidaridad obrera y militante, esconde algo más. Es heredera de unas formas de protesta colectiva "tradicionales" que poco tuvieron que ver con la conflictividad socio-laboral, la crisis de las subsistencias o el desarrollo de la política local, sino

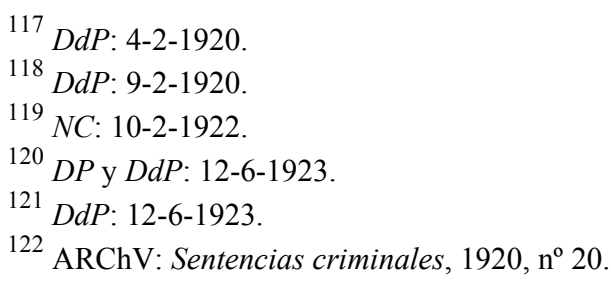


que más bien son reflejo de la solidaridad comunitaria y de la defensa de los rasgos de la identidad local. Hablamos de las acciones de «justicia popular» ${ }^{123}$.

En nuestra comarca de estudio, encontramos otros ejemplos más claros de este tipo de acciones donde, por ejemplo, se defendían a los integrantes de la comunidad frente a agresiones externas. En Cerecinos de Campos se amotinó el vecindario contra dos vecinos del pueblo leonés de Culebras porque "agredieron e insultaron a José de Vega Rondo y Celestino Cabiero Gaitón", habitantes éstos de dicho Cerecinos. "Los amotinados trataron de asaltar la casa donde los agresores estaban detenidos, con el fin de lincharlos" ${ }^{124}$. Y en Villaherreros, el 31 de octubre de 1923, tuvieron que intervenir las autoridades para evitar que buena parte del vecindario agrediera a los integrantes de un circo ambulante de serbios, linchamiento originado porque un oso perteneciente a dicho espectáculo arremetió y lesionó gravemente a un niño de la localidad ${ }^{125}$.

Otro ejemplo este tipo de protesta colectiva "tradicional" eran las cencerradas. Éstas eran expresiones de protesta que tenían como objeto señalar y avergonzar al individuo que cometía alguna ofensa contra las normas morales de la comunidad, principalmente contra los matrimonios en los que uno de los contrayentes era viudo ${ }^{126}$; o, particularmente en el sector palentino de la comarca, a bodas celebradas en épocas tabúes ${ }^{127}$. Ejemplos de esta acción moralizadora, con alto raigambre en la sociedad tradicional, fueron los sucesos ocurridos en noviembre de 1918 en Cerecinos de Campos cuando varios mozos dieron una cencerrada "con pretexto de estar concertado el matrimonio de una hija de Macario Gangoso con un viudo" ${ }^{28}$; o en Osorno, en septiembre de 1922, donde:

123 Otros ejemplos de acciones en defensa de una «justicia popular» ya han sido estudiados por Baumeister, M. (1996). Campesinos sin tierra ..., pp. 244-246; Lucea Ayala, V. (2005). Rebeldes y amotinados..., pp. 305-312; y BASCUÑÁN AÑOvER, O. (2008). Protesta y supervivencia ..., pp. 154161.

${ }^{124} H Z: 11-12-1917$.

${ }^{125}$ DP: 5-11-1923.

126 Thompson, E. P. (2000). Costumbres en común. Barcelona: Crítica, pp. 520-594.

127 "En Frechilla, Mazuecos y otros pueblos palentinos propinan cencerradas a toda boda de jóvenes o viejos, de solteros o viudos, entre San Antón y Carnaval. Es una época tabú para casarse"; en CASAS GaSPAR, E. (1947). Costumbres españolas de nacimiento, noviazgo, casamiento y muerte. Madrid: [s.n.], p. 315.

${ }^{128}$ AHPZ: Sentencias criminales, año 1919, $\mathrm{n}^{\circ} 13$. 
«..., un grupo de diez y nueve jóvenes, con el pretexto de dar una cencerrada al vecino de la misma localidad Juan Pérez Fuente, le dirigieron algunos insultos, viéndose obligada a intervenir la Benemérita» ${ }^{129}$

\section{A MODO DE CONCLUSIÓN}

El análisis de una comarca castellano-leonesa como la Tierra de Campos nos ha permitido ver cómo una región de la España rural del interior, donde triunfó de manera patente el sindicalismo católico-agrario, no fue una laguna de paz social en medio de la convulsa España de los años 1917-1923. Al contrario, los campesinos terracampinos utilizaron las acciones de protesta colectiva para reclamar y exigir sus reivindicaciones y expresar sus opiniones ante conflictos de todo tipo y causa. $\mathrm{Y}$, si bien no puede hablarse de una levantamiento generalizado ni revolucionario, tampoco se puede sostener el estereotipo de un campesinado castellano-leonés sumiso y apático a la crisis política, social y económica de los últimos años del sistema parlamentario de la Restauración. Una conflictividad en la que, si bien tuvo un principal protagonismo el movimiento obrero -el cual aglutinó en torno a sus asociaciones locales a buena parte de los obreros agrícolas de los principales núcleos de población, reflejo del desarrollo de una identidad de clase entre los jornaleros de la comarca-, ni el campesino ni la comunidad local olvidaron las tradicionales formas populares de protesta colectiva propias del siglo XIX.

Por otro lado, el reflejo de esta conflictividad que, atendiendo a la historiografía que hemos señalado en el texto, también tuvo un importante desarrollo en otras regiones de la España agrícola del interior, nos permite señalar que el conflicto campesino, comúnmente vinculado al contexto de la II República, tuvo un origen anterior, extendiéndose y formando parte de la vida de la España rural durante buena parte de la contemporaneidad, formando parte de los procesos de cambio estructural que estaban transformando a las sociedades europeas de la época.

${ }^{129}$ DP: $25-9-1922$. 
